\title{
Efficiency of Electrical Stunning by Electronarcosis: Current Situation and Perspective of Improvement in a Medium-Size Processing Plant
}

\section{-Author(s)}

\section{Barbosa RL' \\ Adamczuk GO \\ Dvojatzki PIII \\ Trentin MGIV}

Lima JD ${ }^{\vee}$

Federal Technologic University of Parana (UTFPR), Academic Department of Mechanics, Rodovia PR 469, Km 1, CEP 85503390 Pato Branco, PR. E-mail: rodrigolb.sc@gmail.com

" Federal Technologic University of Parana (UTFPR), Academic Department of Mechanics, Rodovia PR 469, Km 1, CEP 85503390 Pato Branco, PR. E-mail: gilson@ utfpr.edu.br

III Federal Technologic University of Parana (UTFPR), Coordination of Industrial Engineering lato sensu Specialization, E-mail: dvojatzkipricila@gmail.com

Iv Federal Technologic University of Parana (UTFPR), Academic Department of Electricity, E-mail: marcelo@utfpr.edu.br

Federal Technologic University of Parana (UTFPR), Academic Department of Mathematics. E-mail: donizetti@utfpr.edu. br

\section{Mail Address}

Corresponding author e-mail address Gilson Adamczuk

Federal Technologic University of Parana (UTFPR), Academic Department of Mechanics, Rodovia PR 469, Km 1 85503390. Pato Branco, PR, Brazil Email: gilson@utfpr.edu.br

\section{-Keywords}

Broilers, animal welfare, electric stunning by electronarcosis, stunning severity index, Statistical Process Control, control charts.

\section{ABSTRACT}

The objective of this study was to evaluate the efficiency of electrical stunning by electronarcosis in a medium-size poultry processing plant located in southern Brazil. The current measurement of this type of stunning is presented, and then improvements to this method are proposed. Data were collected for 90 days. A quality indicator was proposed: the Stunning Severity Index (SSI), which includes elements of Statistical Process Control (SPC) using a p-chart (proportion chart) and measures. This index comprises the variables "wing-flapping," "arched head," and "rhythmic breathing." Using the proposed index, 5\% of the birds, on average, presented inefficient stunning symptoms.

\section{INTRODUCTION}

Brazilian poultry processing plants began to adapt their processes in order to comply with the requirements of the European Union and Asian consumer markets. Two essential factors are required for the accreditation of processing plants for exports: animal welfare assurance and humane slaughter (CE, 2009). The increasing importance of animal welfare for the animal processing industry has resulted in changes in animal handling and slaughter practices. Consumers are becoming increasingly aware of animal welfare issues, and have started to demand the adoption of methods that mitigate animal suffering during slaughter (Elrom, 2000). However, welfare concerns must be addressed using technical approaches, such as those proposed in a study on the effects of lighting in the shackling area on broiler welfare (Adamczuk, 2014).

Electrical stunning is not always fully effective, and some broilers may not be properly stunned before bleeding. This is a major welfare concern, in addition of negatively affecting meat quality (Raj, 1998).

Inefficient stunning may cause pain and suffering to the broilers, and increase the incidence of fractures, blood spots, and other meat-quality defects, resulting in significant losses for the processing plant. Several different parameters have been used to determine broiler unconsciousness and insensitivity after stunning, including somatosensory (physical) parameters, such as eyelid reflex (blinking reflex), pupil dilation, wing flapping, absence of voltage in the neck; heart parameters, such as ventricular fibrillation and cardiac arrest as determined by electrocardiogram (ECG); rhythmic breathing by direct or indirect observation of breathing and cloacal movements, respectively; and neurological signs (Kristensen et al., 2007; Koknaroglu, Akunal, 2013).

Three methods are currently applied for stunning/killing broilers in processing plants: electronarcosis (unconsciousness), electrocution (death), and stunning in modified atmosphere (Gregory, 2005; Komiyama et al., 2006). 
In water-bath electric stunning systems, broilers shackled in the line are continuously immersed in the electrified water tank. Voltage is applied between a submerged electrode and the earth, and when the birds are immersed in the tank a circuit is created. However, much of the electric current is lost when transferred from the submerged electrode to ground due to resistance created by each broiler, and the brain receives only a small percentage of the current (10-28\%). The average current applied to a group of broilers in the water tank should be sufficient to efficiently stun every bird that comes out of the tank (Ludtke et al., 2010). However, differences in body resistance should be taken into account, making it difficult to apply a single electric current (Raj, 1998).

The electric current that reaches the brain must be sufficiently strong to induce epileptic seizure. In general, the current is lower than that required for ventricular fibrillation and, therefore, death by electrocution. Insufficient currents may physically immobilize the broiler, but cannot prevent the perception of pain, stress, or discomfort by the animal. Thus, if bleeding does not occur rapidly, broilers may recover consciousness (Bilgili, 1999).

Electric voltage is constant in most commercial stunners, and may be adjusted by the operator. However, it is the current that causes stunning. Thus, from the animal welfare standpoint, electric current is more important than voltage (Castellini et al., 2012). Current variation may be linked to factors that affect the body resistance, such as bird body size and weight, processing line speed relative to water tank length, and the applied frequency (Ludtke et al., 2010). The use of the recommended electric current for stunning reduces meat quality defects, and complies with humane slaughter requirements (Clark et al., 2006). Despite the development of electric stunners using continuous current, providing a separate current for each broiler in the water bath, electric stunning or electronarcosis still apply constant voltage in most commercial processing plants (Grandin, 2010).

Any broiler body part that contacts the electrified water will result in pain and agitation, and sometimes broilers arch their necks, preventing their heads from immersing in the water and receiving the electrical current.

High frequency $(>450 \mathrm{~Hz})$ electric stunning has been used in replacement of low frequency systems (50 or $60 \mathrm{~Hz}$ ), producing lower initial spiking and more even and muscular contraction when the current is applied (Gregory, 2005). The main advantages of using high frequency is reduction of blood spots and other hemorrhages in the carcass, possibly as a result of lower muscular voltage during stunning. High frequency stunning may also reduce blood retention in the viscera, increasing liver yield. In addition, stunning is faster and, depending on the current intensity, the broiler can be more efficiently stunned (Komiyama et al., 2006; Ciobanu et al., 2013).

The duration of stunning depends on the electric current amount and frequency, how long birds remain immersed in water, processing line speed, water tank length, body resistance, and depth of immersion. A shallow immersion (up to the base of the wings) requires higher voltage than a deep immersion (above the base of the wings), since much of the current is lost (ABEF, 2014).

This article proposes of a method to evaluate the effectiveness of broiler stunning by electronarcosis according to a novel indicator, the Stunning Severity Index (SSI).

\section{MATERIALS AND METHODS}

This study was carried out in broiler integration located in the state of Parana, Brazil. Their processing plant slaughters 90,000 broilers per day, with a conveyor line speed of 11,000 broilers/hour in daily production shifts of 8 hours. The company owns a feed mill, an incubatory four grandparent farms and 10 breeder farms. Broilers are produced by approximately 200 contracted farmers.

The study was conducted between August 2014 and November 2014 in three stages. In the first period, the current stunning efficiency and the behavior of broilers leaving the water tank was analyzed to assess the current situation. Data collected for 60 days using the company's spreadsheet template to check stunning efficiency were analyzed.

Table 1 - Stunning efficiency parameters

\begin{tabular}{ll}
\hline Parameter & Measurements \\
\hline $\begin{array}{l}\text { Stunner voltage, current, and } \\
\text { frequency }\end{array}$ & $\begin{array}{l}\text { Record the parameters shown on the } \\
\text { screen located in the shackling area. }\end{array}$ \\
\hline Blinking eyes & $\begin{array}{l}\text { N. of broilers blinking their eyes at the } \\
\text { exit of the water tank }\end{array}$ \\
Wing-flapping & N. of broilers opening and closing wings \\
\hline Arched head & N. of broilers with arched head \\
Rhythmic breathing & $\begin{array}{l}\text { N. of broilers presenting cloaca } \\
\text { movements }\end{array}$ \\
\hline $\begin{array}{l}\text { Vocalization } \\
\text { Total of broilers analyzed for parameter }\end{array}$ & N. of broilers vocalizing after neck cutting \\
\hline
\end{tabular}


In the second stage, a review and the redesign of the currently used animal welfare monitoring method was proposed (Table 1). In the third stage, the Stunning Severity Index (SSI) is proposed.

\section{RESULTS}

\section{Current situation}

Flocks were straight run until May 2014. In June, chicks started to be sexed, and male Cobb 500 broilers became the standard for processing. The slaughter process starts with the shackling of broilers in the conveyor line. The line comprises 16 shackles to match the processing speed, which is of 11,000 broilers/hour with no empty shackles. The conveyor line is equipped metal shackles, spaced at six inches, and a breast rub along the shackling line to reduce bird stress.

Broilers are stunned by immersion in a water tank electric stunner. The water tank is $5-\mathrm{m}$ long, has a capacity for 21 broilers, and applies continuous electric current. No compounds, such as salt, are added to improve shock effectiveness.

The recommended parameters for broilers (Gregory, 2005) of a current of $120 \mathrm{~mA} / \mathrm{bird}$, a voltage range between 60 and 80 Volts, and a maximum frequency of $800 \mathrm{~Hz}$ were applied. However, the stunning was not effective as flock weight was not uniform.

In order to monitor stunning effectiveness, an operator in the shackling area monitor stunning tank water level, aiming at preventing bird fractures or burns. Also, the stunning parameters (electric current, voltage, and frequency) are adjusted to according to bird weight (raising the water level for small broilers and lowering it for big broilers). Stunning effectiveness is also checked by a employee of the quality control department that monitors the reception area, following the procedures of an official Self-Control Program, required by the Ministry of Agriculture (MAPA, 2005). The quality-control employee uses specific spreadsheets for monitoring, which contain monitoring instructions and control frequency. Deviations from the parameters set in the spreadsheet are reported to the staff responsible for the sector in order to undertake needed actions to correct the non-conformity.

The following parameters are monitored by the quality sector:

- Processing speed: the values on the digital screen located in the slaughter supervision room are recorded;

- Stunning voltage, current, and frequency shown on the digital screen in the shackling area are recorded. Current oscillates as a function of the conveyor line speed and level of bird agitation at the entry into the water bath, ant therefore, current is never stable;

- If water spills to the sides of the water tank, "yes" is recorded; otherwise, "no" is recorded;

- The time interval from shackling to entry in the water tank, time interval of permanence in the water tank, and time at the exit of the water tank are recorded. The time interval from shackling to entry in the water tank starts to be recorded when the shackling operation leader marks one shackle and informs the quality employee by radio, and ends when the marked shackle arrives at the water tank. The other times are monitored by the quality employee, who identifies as hackle and follow it until the final point.

Stunning effectiveness is determined by individually observing 50 broilers/hour and recording the number of broilers that present blinking eyes, wing-flapping, arched head, rhythmic breathing, and/or vocalization on the spreadsheet. Additionally, the negative and positive results of each parameter is to determine stunning effectiveness is critically analyzed (Table 2).

Table $\mathbf{2}$ - Critical analysis of aspects of checking the efficiency of the electric stunner

\begin{tabular}{ll}
\hline Parameter & Critical Analysis \\
\hline Blinking eyes & $\begin{array}{l}\text { Important for humane slaughter, since the bird } \\
\text { However, it is difficult to determine, due to } \\
\text { conveyor line speed and low light intensity of the } \\
\text { shackling area, and therefore, the results are not } \\
\text { reliable. }\end{array}$ \\
It is one the most important parameters for \\
stunning effectiveness evaluation, as it is easy to \\
observe, which makes it results highly reliable. \\
Hing-flapping
\end{tabular}$\quad \begin{aligned} & \text { However, it should be differentiated from wing- } \\
& \text { flapping due to muscle spasms, which are not } \\
& \text { considered as a result of deficient stunning. } \\
& \text { Easched head }\end{aligned}$

All monitored parameters complied with the thresholds, except for conveyor line speed and period of permanence in the water tank. When deviations are detected, the quality employee issues a noncompliance report on the back of the spreadsheet and transmit it to the staff responsible to describe the actions taken to correct them.

The stunning monitoring spreadsheet had been used since 2012, and needed to be updated, implementing 
representative sampling and parameters simple to analyzed, not interfering with the slaughter process, conveyor line speed, and lighting.

Table 3 shows Pearson's correlation coefficients of dependent variables for a conveyor line speed of 11,000 broilers/hour(blinking eyes, wing-flapping, arched head, and rhythmic breathing) relative to independent variables (current, frequency, and average broiler body weight).

Table 3-Correlations between dependent and independent variables of stunning

\begin{tabular}{lccc}
\hline Dependent Variable & \multicolumn{3}{c}{ Independent Variable } \\
\hline & Current (A) & Frequency (Hz) & Average weight $(\mathrm{kg})$ \\
\hline Wing-flapping & $-0.09^{\mathrm{a}}$ & $-0.05^{\mathrm{a}}$ & $0.19^{\mathrm{b}}$ \\
Rhythmic breathing & $0.042^{\mathrm{a}}$ & $-0.12^{\mathrm{a}}$ & $0.20^{\mathrm{b}}$ \\
Arched neck & $0.049^{\mathrm{a}}$ & $-0.02^{\mathrm{a}}$ & $0.17^{\mathrm{b}}$ \\
Blinking eyes & $-0.126^{\mathrm{a}}$ & $-0.16^{\mathrm{b}}$ & $0.31^{\mathrm{b}}$ \\
\hline
\end{tabular}

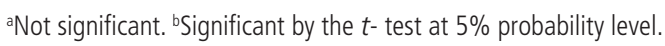

The correlation analysis showed that all dependent variables were statistically and positively correlated with average broiler body weight, indicating it has the greatest impact on stunning effectiveness. Blinking eyes were negatively correlated with stunning electric frequency. Considering that male and female broilers typically present different body weight at slaughter, sexing at hatch, and rearing single-sex flocks may increase stunning effectiveness, and therefore should be considered by the company under study.

After assessing the current situation, the monitoring method was reviewed and improvements were proposed. Relative to shackling and stunning, some measures could be taken in terms of sampling and analyses.

Sample size $n_{1}$ may be determined according to Barbetta et al., (2010): a proportion $p$ of the population $\pi$ needs to sampled in order to determine the proportion of broilers that are not effectively stunned. The sample size is calculated as Equation 1:

$$
n_{t}=\frac{z^{2}(\pi) \cdot(1-\pi)}{(p-\pi)^{2}}
$$

Where $(p-\pi)$ is the error and $z$ is the confidence level. Therefore, based on a typical 95\% average confidence level, $z=1.96$. The equation (1) shows that the larger the population $\pi$ not effectively stunned, the larger the sample size. This applies to $\pi$ values up to 0.5, above which sample size decreases. Also, according to Barbetta et al., (2010), a sampling error $(p-\pi)$ in the range of 0.025 to 0.03 is acceptable to obtain the maximum population variance value.
Therefore, in the evaluated processing plant, a sample size of 1,067 to 1,450 broilers is suggested. Considering the line speed of 11,000 broilers/hour and 8-h daily shifts, data should be collected for 1 minute per hour, totaling 180 broilers/min, corresponding to $1.63 \%$ of the total number of broilers in 1 hour. This amounts to 1,460 broilers analyzed per day, divided into eight samples of 1 minute per hour, which would allow for collecting data on all possible dimensions (flock, sex, average body weight, weather conditions throughout the day, etc.). Hourly sample collection would also allow using Statistical Process Control (SPC) tools. There is the possibility, according to the company, to collect and evaluate the proposed samples with the aid of one worker during a one-month period.

Additionally, improvements in the processing plant under study were proposed, including:

- Regular training at every six months of all employees working in the reception, stunning, and bleeding areas;

- Improve feet cutting effectiveness in the featherplucking area to prevent feet returning in the shackles to the reception area, which causes delays in shackling and reduces line speed.

- Monitoring if shackles are wet before entering the water bath;

- Evaluation of flock uniformity and feet size when shackling;

- Placement of a metal slope to support the broiler's head and better direct the birds to the entry of the stunning water bath;

- Testing stunning with two water tank levels: shallow immersion (up to the base of wings) or deep immersion (above the base of wings);

- Implementing the Stunning Severity Index and the control chart for the electrolytic water bath.

As the shackling area uses natural and/or blue light in order to meet animal welfare recommendations, as the use of artificial white light is not allowed, the lighting conditions at the stunner observed on the days when the survey was carried out and the slaughter speed of 11,000 broilers/hour, it was very difficult to monitor the parameter "blinking eyes". Therefore, the data recorded for this parameter was not considered reliable. According to literature, the "absence of vocalization" indicated effective stunning and bleeding. However, no vocalization was observed during any of the monitoring periods.

After 30 days of observation, some monitoring improvements were suggested, as shown in Table 4. 
Barbosa RL, Adamczuk GO,

Dvojatzki P, Trentin MG, Lima JD
Efficiency of Electrical Stunning by Electronarcosis: Current Situation and Perspective of Improvement in a Medium-Size Processing Plant
Table 4 - Suggestions for the improvement of monitoring stunning effectiveness.

\begin{tabular}{ll}
\hline Parameter & Suggestion for Improvement \\
\hline $\begin{array}{l}\text { Stunner voltage, } \\
\text { current, and frequency }\end{array}$ & $\begin{array}{l}\text { Indicate in the spreadsheet if data shown on } \\
\text { the screen correspond to each monitored } \\
\text { broiler. }\end{array}$ \\
\hline Blinking eyes & $\begin{array}{l}\text { Remove this parameter from the daily } \\
\text { spreadsheets and include it in the monthly } \\
\text { spreadsheet of the qualitative animal welfare } \\
\text { Check List. }\end{array}$ \\
Wing-flapping & $\begin{array}{l}\text { Change the number of samples to match the } \\
\text { line speed of 11,000 broilers/hour. }\end{array}$ \\
Arched head & $\begin{array}{l}\text { Change the number of samples to match the } \\
\text { line speed of 11,000 broilers/hour } \\
\text { Change the number of samples to match the } \\
\text { line speed of 11,000 broilers/hour }\end{array}$ \\
Focalization & $\begin{array}{l}\text { Remove this parameter from the spreadsheets. } \\
\text { Check if the birds' feet are correctly placed in } \\
\text { the shackles. }\end{array}$ \\
Shackling & $\begin{array}{l}\text { Check if both feet are shackled and no foot has } \\
\text { returned from the plucking area. }\end{array}$ \\
Flock weight & $\begin{array}{l}\text { Record flock weight in the spreadsheet } \\
\text { to include it in the stunning effectiveness } \\
\text { assessment. }\end{array}$ \\
\hline
\end{tabular}

Finally, the inclusion of a Statistical Process Control Program (SPC) is suggested in the current stunning assessment spreadsheet. Montgomery (2004) described an approach to reduce process variability by implementing a control chart, which establishes the application of useful continuous process improvement tools, also allowing for continuous training of the employees.

Considering the need to measure stunning effectiveness, a Stunning Severity Index - SSI (2) is proposed. In this index, the dependent variables $\left(F_{w}-\right.$ Wing-flapping, $A_{h}$ - Arched head, and $R_{b}$ - Rhythmic breathing),i.e., all stunning parameters are jointly analyzed for each sample. The rationale is that, all those parameters $\left(F_{w}, A_{h}\right.$, and $\left.R_{b}\right)$ individually provide an indication of stunning effectiveness. Because eye blinking is difficult to measure and, therefore, unreliable, it was not included in the calculation of the SSI, Equation 2.

$$
S S I=\frac{F_{w}+A_{b}+R_{b}}{\left(n_{t} / h_{t}\right)}
$$

Where $h_{t}$ is the number of hours of work in one day and $\left(n_{t} / h_{t}\right)$ represents the number of broilers monitored during one minute per hour for the three aforementioned parameters. In the studied case, the sample included 180 broilers.

The joint data collection of this index (SSI) allows for analyzing stunning by the Statistical Process Control (SPC). Since the SSI is a proportion, a p-chart may be used. According to Montgomery (2004), the p-chart involves the fraction of non-uniform and/or defective products in a sample, where the range of considerable size is from 50 to 200 units. Additionally, the sampling frequency must be according to production shifts, i.e., one sample per shift, one sample per equipment set, or 1 sample per hour. The standard deviation of nonconformity products is calculated by Eq. 3, and the upper control limit (UCL) and the lower control limit $(\mathrm{LCL})$ are calculated by Eq. 4 and Eq. 5, respectively.

$$
\begin{aligned}
\sigma_{p i} & =\frac{\sqrt{\bar{p} \cdot(1-\bar{p})}}{\sqrt{n_{i}}} \\
U C L & =\bar{p}+3 . \sigma_{p i} \\
L C L & =\bar{p}-3 . \sigma_{p i}
\end{aligned}
$$

Where $n_{i}$ is the sample size and $\bar{p}=S S /$ represents the average percentage of non-conformities (in this case, not properly stunned broilers). This value may be used as the starting point for improvement. Points above the Upper Control Limit (UCL) characterize the occurrence of a special cause to be investigated (flock, average body weight, and stunner parameter deviations in that instance, etc.).

The use of control charts involves two stages: initial study and control. A chart is created in the initial study, observing if there are any points out of control. After investigating and correcting all causes of deviation, the SSI is then monitored, intervening when a deviation occurs.

As an example of the initial study, Figure 1 shows the SSI p-chart in the studied company from August 2014 to November 2014, still using the current stunning monitoring system (50 broilers per parameter per hour $=150$ ). Then, the following chart (Figure 1) demonstrates the application of SSI.

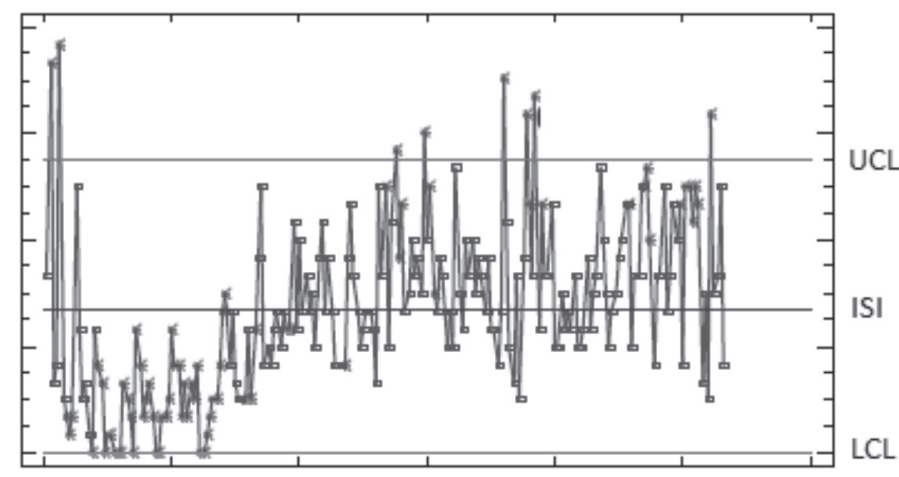

Figure 1 - Example of SSI application with p chart (August 2014 to November 2014).

Some points out of control are shown Figure 1, and may be considered the starting points detected in the initial study. During the analyzed period, 5\% 
of the broilers, on average, were not effectively stunned. Although this is a preliminary analysis, the cause of values above $11 \%$ (UCL) would need to be investigated. Thus, the SSI, in addition of integrating 3 dependent variables $\left(F_{w}, A_{h}\right.$, and $\left.R_{b}\right)$ through SPC, may aid the monitoring of this important stage of broiler processing.

\section{CONCLUSIONS}

Initially, the current process of measuring stunning effectiveness was presented. Improvement measures and a review of the current method were proposed, including simultaneous collection of data on all stunning parameters for one minute per processing hour. Thus, the objective is to capture all strata in one day of slaughtering. Finally, the use of a Statistical Process Control tool, the Stunning Severity Index (SSI), by means of using the p-chart, was proposed as quality indicator.

The SSI should include the parameters "wingflapping," "arched head," and "rhythmic breathing". Using SSI, it was observed that $5 \%$ of the broilers, on average, were not effectively stunned. A preliminary analysis indicated that the causes of SSI values above $11 \%$ (UCL) should be investigated.

\section{REFERENCES}

ABEF. Annual Report 2014 [cited 2014 Dez 11]. São Paulo: Associação Brasileira dos Produtores e Exportadores de Frangos; 2014. Available from: http://www.abef.com.br.

Adamczuk GO, Trentin MG, Lima JD de, Motta J, Cantelli RP. Lighting in the shackling area: conciliating broiler welfare with labor comfort. Brazilian Journal of Poultry Science 2014;16(2):87-92.

Barbetta PA, Bornia AC, Reis MM. Estatística: para cursos de engenharia e informática. São Paulo: Atlas; 2010.

Bilgili SF. Recent advances in electrical stunning. Poultry Science 1999;78:282-286,

Castellini C, Boggia A, Cortina C, Dal Bosco A, Paolotti L, Novelli E, et al. A multicriteria approach for measuring the sustainability of different poultry production systems. Journal of Cleaner Production 2012;37:192-201.

Ciobanu MM, Corneliu BP, Roxana L, Narcisa PA, Elena S, Teodor B, et al. Influence of electrical stunning voltage on bleed out, sensory parameters and color in chicken meat quality. Current Opinion in Biotechnology 2013;245:S89.
Clark JAM, Potter M, Harding E. The welfare implications of animal breeding and breeding technologies in commercial agriculture. Livestock Science 2006;103:270-281.

Conselho Europeu. Regulamento (CE) 1099/2009: Proteção dos animais no momento da occisão. Jornal Oficial da União Europeia; 2009.

Elrom K. Handling and transportation of broilers welfare, stress, fear and meat quality - Part I: Rearing of broilers and the role of welfare. Israel Journal of Veterinary Medicine 2000;55(1).

Grandin T. Auditing animal welfare at slaughter plants. Journal Meat Science 2010;86:56-65.

Gregory NG. Recent concerns about stunning and slaughter. Meat Science 2005:70:481-491.

Koknaroglu H, Akunal T. Animal welfare: an animal science approach. Meat Science 2013;95:821-827.

Komiyama CM, Ludtke C, Silveira ETF. Manejo pré-abate e seus Efeitos no bem-estar e qualidade da carcaça e carne [cited 2015 Mar 3] Revista Avicultura Industrial 2006:1143. Available from: http://www. aviculturaindustrial.com.br.

Kristensen HH, Prescott NB, Perry GC, Ladewig J, Ersbøll AK, Overvad KC, et al. The behaviour of broiler chickens in different light sources and illuminances. Applied Animal Behaviour Science 2007;103:75-89.

Ludtke CB, Ciocca JRP, Dandin T, Barbalho PC, Vilela JA. Abate humanitário de aves [cited 2014 Dez 13]. World Society for the Protection of Animals; 2010. Available from: http://www.agricultura.gov.br/arq editor/Abate\%20H_\%20de\%20Aves\%20-\%20WSPA\%20Brasil.pdf

MAPA. Ministério da Agricultura, Pecuária e Abastecimento da Secretaria de Defesa Agropecuária. Portaria 210, de 10 de novembro1998. Regulamento Técnico da Inspeção Tecnológica e Higiênico-Sanitária de Carne de Aves [cited 2014 Dez 14]. Sistema de Legislação Agrícola Federal. Available from: http://extranet.agricultura.gov.br/ sislegisconsulta/consultarLegislacao.do.

MAPA. Ministério da Agricultura, Pecuária e Abastecimento. Decreto 30.691, de 29 de maio de 1952. Regulamento da Inspeção Industrial e Sanitária de Produtos de Origem Animal - RIISPOA [cited 2014 Dez 14]. Sistema de Legislação Agrícola Federal. Available from: http://extranet. agricultura.gov.br/sislegis-consulta/consultarLegislacao.do.

MAPA. Ministério da Agricultura, Pecuária e Abastecimento. Instrução normativa $n^{\circ} 3$, de 17 de janeiro de 2000. Regulamento técnico de métodos de insensibilização para o abate humanitário de animais de açougue [cited 2014 Dez 14]. Sistema de Legislação Agrícola Federal. Secretaria de defesa agropecuária. Available from: http://extranet. agricultura.gov.br/sislegis-consulta/consultarLegislacao.do.

Montgomery DC. Introdução ao controle estatístico da qualidade. $4^{\mathrm{a}}$ ed. Rio de Janeiro: LTC; 2004

Raj M. Welfare curing stunning and slaughter of poultry. Poultry Science $1998 ; 77: 1815-1819$. 